\title{
Action Through Thought: The Ethics of Inquiry
}

Charles S. Peirce is credited with being the father of the pragmatic movement, to date America's only indigenous philosophy. Yet I suspect that his thought might be judged by some to be "un-American" because it does not live up to the stereotype of "American" fairly widespread both here and abroad. According to this popular view Americans are the great technicians; they have the know-how; they are successful in the practical world of business, commerce, and industry. But as speculative thinkers, as men of cosmic vision, Americans are a sorry lot! Not a Kant, not a Hegel among them! I hope this consideration of Peirce will challenge such a view by showing that Peirce's pragmaticism is as sophisticated and serious as any philosophical movement abroad, and indeed more so than some. The "American Mind," to use Emerson's phrase, is speculative, complex, and rich, and we ought not sell it short.

Permit me to mention some of Peirce's philosophical views which, according to the popular stereotype, might be considered quite "un-American." Peirce held a version of "scholastic" realism against nominalism in all its forms. Further, he was convinced that metaphysics is a genuine theoretical science and that physical science receives its principles of investigation from philosophy. $\mathrm{He}$ held that theory and practice should have nothing immediately to do with each other; that higher education is not primarily for teaching but for research (the principle way of learning); that action is not the end-all and be-all of thought; that pleasure, success, better

An earlier version of this chapter appeared as "Charles S. Peirce: Action Through Thought-The Ethics of Experience," in Doctrine and Experience, ed. Vincent G. Potter (New York: Fordham University Press, 1988). 
living are not properly and specifically human goals at all. In short, Peirce, the pragmatist, in the name of that very method, had to foreswear the practical, the immediate, the useful as of any real consequence for either science or philosophy. I dare say that this will come as a surprise to many abroad and is already an embarrassment to some American thinkers who pride themselves on being in the mainstream of America's philosophical tradition.

Peirce had a great deal to say about experience, a great deal to say about beliefs. Beliefs are to be brought to the test of experience, and at the same time, insofar as they shape our conduct, beliefs influence what our future experience is likely to be. In a word, Peirce was much concerned about the relation between theory and practice.

I would like, therefore, to take up the following issues: (1) Peirce's separation of theory from practice; (2) the meaning of the pragmatic maxim in terms of "practical consequences"; and (3) Peirce's understanding of the relation between Instinct and Reason as the ground of the ultimate continuity between theory and practice expressed in the maxim.

To begin, then, Peirce consistently and repeatedly maintained not only that theory had nothing whatever to do with practice but also that it ought not have anything to do with it. Peirce makes his most sustained case in this matter in a series of lectures delivered at Harvard in 1898. Let me give some background to those lectures. ${ }^{1}$

During the spring and summer of 1897 Peirce worked on eight lectures to be given at Cambridge as a result of William James's efforts to bring him to the Harvard campus in some capacity or other. Two years earlier James had unsuccessfully intervened on Peirce's behalf, asking President Eliot to appoint him to a permanent chair in the Philosophy of Nature. Eliot flatly refused even to have Peirce considered, and so James had to settle for inviting him to give a lecture series. In December 1897, Peirce sent James an outline of the eight lectures - all of them on logic. James wrote back lamenting the choice of topic since "there are only three men who could possibly follow your graphs and relatives."' In a most friendly way, and out of the sole motive of having Peirce's series be a success, James advised Peirce to " "be a good boy and think a more popular plan out" - one that would hold the audi- 
ence's interest. James remarks, “'Separate topics of a vitally important character would do perfectly well."

Peirce's reaction was predictable. He was deeply hurt and disappointed. He wrote back accepting the conditions without enthusiasm and without holding out any hope that he could thus give his hearers any idea or account of his philosophy since it reposed "entirely upon the theory of logic." He remarks that no doubt James has gauged the capacity of his students correctly and that "it agrees with all I hear and the little I have seen of Cambridge."” He cannot resist comparing the Harvard students with those whom he tutored in New York City for whom, he tells James, the method of graphs proved quite easy because their minds were stimulated by New York life. “'Your Harvard students of philosophy find it too arduous a matter to reason exactly. Soon your engineers will find it better to leave great works unbuilt rather than go through the necessary calculations."”

Peirce set to work redoing the entire series. He entitled this revision "Detached Ideas on Topics of Vital Importance," but it was advertised in Cambridge under the inoffensive title "Reasoning and the Logic of Things." Despite James's suggestions a great deal of logic found its way into those lectures. Royce wrote to James that they put him on a completely new direction. ${ }^{2}$ It was also the occasion for some of Peirce's most ironic remarks on "the practical" in education.

Consider the title Peirce suggested for the series. Nothing could be more foreign to his view of philosophy than a set of "detached ideas," and nothing could be less promising a subject for philosophical discourse than "vitally important topics." If one thing is clear, it is that Peirce thought philosophy must be done systematically. Further, philosophy had little or no immediate relevance for "life" and its vital concerns. According to Peirce:

Philosophy is that branch of positive science (i.e., an investigating theoretical science which inquires what is the fact, in contradistinction to mathematics which merely seeks to know what follows from certain hypotheses) which makes no (special) observations but which contents itself with so much of experience as pours in upon every man during every hour of his waking life. $(5.13 \text {, note })^{3}$

Philosophy has three branches: Phenomenology, Normative Science, and Metaphysics. These are related to each other as first, 
second, and third. Metaphysics involves the other two and is the science of the Real par excellence. ${ }^{4}$ Yet Peirce is fond of saying that metaphysics is gibberish, and meaningless, not intrinsically but because of its backward state. That backward state is due fundamentally to the neglect of Kant's advice to build metaphysics architectonically, that is, in the manner in which a house is constructed - on a broad and solid base and out of materials tested for the purpose (see, for example, 1.176-179, 5.5, 6.7-34). This architectonic structure must be put together with exact logical care.

What is needed above all, for metaphysics, is thorough and mature thinking; and the particular requisite for success in the critic of arguments is exact and diagrammatic thinking. (3.406)

In a word, there can be no sound metaphysics unless it be systematic and based on logic. Finally, metaphysics can advance if and only if it is done by "laboratory men" whose sole motivation is the pursuit of truth wherever it may be found (see, for example, 5.412, 1.618-620). Furthermore, the purpose of any theory is "to furnish a rational account of its object" (2.1), and so theory aims directly at nothing but knowledge.

Here Peirce is combatting two rather common views of theoretical investigation. The first we might call the "doctrinaire view" and the second the "utilitarian view." According to the first, science and philosophy are looked upon as a body of acquired truth to be taught and to be learned in the interest of instructing and of bettering mankind. The possession of this truth is expected to have immediate beneficial effects upon individuals and society. According to the second, frequently held in conjunction with the first, the sole legitimate motive for scientific or philosophical inquiry is the application of the results for the immediate personal or social benefit of mankind. Technology becomes science's ultimate motive and justification; ideology becomes philosophy's.

According to Peirce, the doctrinaire view simply misses science as a "living historic entity."

As such it [science] does not consist so much in knowing, nor even in "organized" knowledge, as it does in diligent inquiry into truth for truth's sake, without any axe to grind, nor for the sake of the 
delight of contemplating it, but from an impulse to penetrate into the reason of things. (1.44)

The second view, he contends, corrupts the scientific enterprise from the beginning, because it prejudices the outcome and restricts the extent and scope of research. Such a view might be called "logical hedonism" inasmuch as it falls victim to the same mistake as moral hedonism does. Just as moral hedonism mistakes some form of "pleasure" for the moral good, so logical hedonism mistakes some form of "utility" for the truth. Such an error, in Peirce's view, generally results in achieving neither genuine satisfaction nor authentic utility (see 1.619).

Peirce once said that the pragmatic maxim was nothing but Jesus' recommendation "By their fruits you shall know them" (Matt. 7:20). He might also have justly pointed out that the ethical principle of investigation proposed here is also anticipated by the New Testament, in the parable of the lilies of the field (Matt. 6:2833; Luke 12:27-31). Peirce might have paraphrased it something like this: "Seek first the truth, and all these things will be added to you."

Let us consider Peirce's "topics of vital importance" in some detail. In the first lecture of the Cambridge series, "Philosophy and the Conduct of Life," Peirce remarks that the Greeks

expected philosophy to affect life-not by any slow process of percolation of forms, as we may expect that researches into differential equations, stellar photometry, the taxonomy of echinoderms and the like will ultimately affect the conduct of life-but forthwith in the person and soul of the philosopher himself, rendering him different from ordinary men in his views of right conduct. (1.618)

This I would call the "Immediate Relevance" thesis. ${ }^{5}$ Peirce exempts Aristotle, however, from this mentality because he was not altogether Greek. Peirce continues:

Now, Gentlemen, it behooves me, at the outset of this course, to confess to you that in this respect I stand before you an Aristotelian and a scientific man, condemning with the whole strength of conviction the Hellenic tendency to mingle philosophy with practice. (1.619)

Practice, the conduct of life, utility, what would forthwith make one a better or a more successful person-none of this has or 
should have anything to do with science or philosophy since such an attitude would undermine those disciplines and endanger the moral integrity of their practitioners. The backward state of metaphysics, Peirce thinks, is directly attributable to the fact that it is largely in the hands of "seminary men" who

have been inflamed with a desire to amend the lives of themselves and others, a spirit no doubt more important than the love of science, for men in average situations, but radically unfitting them for the task of scientific investigation. (1.620)

According to Peirce, all men might be put into one of three categories depending on what they considered to be the highest good in life.

If we endeavor to form our conceptions upon history and life, we remark three classes of men. The first consists of those for whom the chief thing is the quality of feelings. These men create art. The second consists in the practical men, who carry on the business of the world. They respect nothing but power, and respect power only so far as it is exercised. The third class consists of men to whom nothing seems great but reason. If force interests them, it is not in its exertion, but in that it has a reason and a law. For men of the first class, nature is a picture; for men of the second class, it is an opportunity; for men of the third class, it is a cosmos, so admirable, that to penetrate to its ways seems to them the only thing that makes life worth living. These are the men whom we see possessed by the passion to learn, just as other men have a passion to teach and to disseminate their influence. If they do not give themselves over completely to their passion to learn, it is because they exercise self-control. Those are the natural scientific men; and they are the only men that have any real success in scientific research. (1.43)

"Vital importance" has two senses, and Peirce's irony depends on the play between them. In the literal sense "vitally important topics" refers to questions of physical life and to well-being in the common course of things. In the extended sense it refers to those questions of ultimate significance which make life worth living at all. If one should think that the literal sense is the only meaning, then neither philosophy nor science need play any role in that person's life. Attention to one's natural sentiments and instincts in these matters will afford one a much better chance of success. On 
the other hand, if one is convinced that coming to know the truth about oneself and about the universe is what makes human life specifically human and thus affords man his only genuine fulfillment, then the pursuit of philosophy and science becomes a way of life and questions of everyday business take a secondary and relatively modest place of importance.

Practice in the sense of "the conduct of life" Peirce would divorce from theory. This includes the entire area of practical affairs, whether such decisions concern ordinary business or great crises.

In the great decisions, I do not believe it is safe to trust to individual reason. In everyday business, reasoning is tolerably successful but I am inclined to think that it is done as well without the aid of theory as with it. A logica utens, like the analytical mechanics resident in the billiard player's nerves, best fulfills familiar uses. (1.623)

But in practical affairs, in matters of vital importance, it is very easy to exaggerate the importance of ratiocination. Man is so vain of his power of reason! . . . It is the instincts, the sentiments, that make the substance of the soul. Cognition is only its surface, its locus of contact with what is external to it. $(1.626,1.628)$

Peirce claimed that he could strictly prove all this, "but only by assuming a logical principle ..." (1.629). According to Peirce, then, Reason itself recommends this attitude toward theory and practice.

Were I willing to make a single exception to the proposition I thus enunciate that theory and practice be kept separate and to admit that there was one study which was at once vitally important and scientific, I should make that exception in favor of logic; for the reason that if we fall into the error of believing that vitally important questions are to be decided by reasoning, the only hope of salvation lies in formal logic, which demonstrates in the clearest manner that reasoning itself testifies to its own ultimate subordination to sentiment. (1.672)

At the same time Peirce observes that if one accept this "conservative sentimentalism" and so modestly rate one's reasoning powers in matters of vital importance, then one would find that the very first command of instinct is that one recognize a higher business than one's own. Thus reason recommends reliance on instinct in 
practical matters, while instinct itself commands that one look beyond the practical.

Thus while reason and the sciences of reasoning strenuously proclaim the subordination of reasoning to sentiment, the very supreme command of sentiment is that man should generalize. . . (1.673)

I will return to this point.

In 1896 William James's The Will to Believe appeared with its touching dedication to Peirce. In these Cambridge lectures Peirce substitutes the "will to learn" for "the will to believe," at least in matters of theoretical investigation.

I hold that what is properly and usually called belief . . has no place in science at all. We believe the proposition we are ready to act upon. . . . But pure science has nothing at all to do with action. . . . (1.635)

This brings me to the second issue: the meaning of "practical consequences" in the pragmatic maxim. There is something paradoxical about Peirce's remark excluding all belief from science. The pragmatic maxim after all was formulated in the context of the fixation of belief. In those early papers Peirce argued that the whole point of inquiry is to fix belief and that scientific method is the best way to do it. How then can he now claim that belief has no place at all in science? As a first step toward making some sense out of this, I think it will help to recall the distinction between science as a lived experience and science as an established body of "truths," that is, of "theoretical beliefs." Genuine doubt, not mere "paper doubt," is the stimulus of scientific inquiry. When the irritation of such doubt is removed, inquiry ceases. Fixation of belief in that sense may be the upshot or outcome of inquiry, but it cannot be its immediate motive. Only the Will to Learn, to pursue genuine doubt wherever it may lead, can play a role in science. To fix belief is to cut off investigation and so is to bring science as a lived enterprise to an end.

Furthermore, Peirce considered the notion of "theoretical belief" to be odd. At best it could mean only that certain scientific laws and theories are provisionally accepted by the scientific community. Only in this sense is there a body of "scientific truths" and so of "theoretical beliefs." 
A practical belief is a habit of deliberate behavior, that upon which we are prepared to act. A theoretical "belief" is an expectation concerning future experience, either actual or merely possible. While it is true that "every proposition that is not pure metaphysical jargon and chatter must have some possible bearing upon practice" (5.539), as the pragmatic maxim says, still it must have some "possible bearing," that is, it must have some conceivable practical consequences. This is true even of pure theoretical propositions. Conceivable practical consequences or possible bearing in practice is quite distinct from practical consequences in the sense of practice-action here and now. In Peirce's words, while every theoretical belief is at least indirectly a practical belief, this is not the whole meaning of a theoretical belief. It is further an expectation or anticipation of future experience, actual or merely possible, not in the sense that it anticipates some muscular sensation (as in a practical belief) but in the sense that it is

the stamp of approval, the act of recognition as one's own, being placed by a deed of the soul upon an imaginary anticipation of experience, so that, if it be fulfilled, ... the person will claim the event as his due, his triumphant "I told you so" implying a right to expect as much from a justly regulated world. (5.540)

Since all beliefs essentially involve expectation (5.542) and so look to the future, so must the theoretical beliefs of science. What is expected from them directly, however, is not some bodily reaction. Indirectly and ultimately, through the mediation of thought, such "muscular sensation" may be anticipated. What is directly anticipated by theoretical belief can only be another thought. Consider some of Peirce's examples.

To say that a quadratic equation that has no real root has two different imaginary roots does not sound as if it could have any relation to experience. Yet it is strictly expectative. It states what would be expectable if we had to deal with quantities expressing the relations between objects, related to one another like the points of the plane of imaginary quantity. So a belief about the incommensurability of the diagonal relates to what is expectable for a person dealing with fractions; although it means nothing at all in regard to what could be expected in physical measurement. . . Riemann declared that infinity has nothing to do with the absence of a limit but relates solely to measure. This means that if a bounded surface be meas- 
ured in a suitable way it will be found infinite, and that if an unbounded surface be measured in a suitable way, it will be found finite. It relates to what is expectable for a person dealing with different systems of measurement. (5.54l)

Similar examples might be drawn from history and theology.

Consequently, even if every proposition must have a reference to some conceivable application to practice in order for it to have any definite meaning at all, still, when the pragmatic maxim is applied to "theoretical beliefs," the "practical consequences" are purely matters of thought. Even in practical life, insofar as they have been articulated and critically scrutinized, practical consequences have been transformed through thought into rules for deliberate (rational) conduct.

It would be too long to repeat here what I have said elsewhere concerning the efforts of Peirce to dissociate himself from other pragmatists whom he thought pushed the maxim too far so as to make action the be-all and end-all of thought. ${ }^{6}$ It is enough to note that Peirce argued to the contrary.

If it be admitted ... that action wants an end, and that that end must be something of a general description, then the spirit of the maxim itself, which is that we must look to the upshot of our concepts in order rightly to apprehend them, would direct us toward something different from practical facts, namely, to general ideas, as the true interpreters of our thought. $(5.3)^{7}$

Peirce's pragmatism recognizes a fundamental connection between thought and action, between theory and practice, but without confusing the two and without inverting the order of the relation. Thought ultimately applies to action and theory ultimately applies to practice, at least in the sense of referring to conceivable action and to conceivable practice. But this is quite different either from making thought to consist in action and theory to consist in practice, or from making thought's ultimate purpose action and theory's ultimate purpose practice. Action through thought is only the upshot of inquiry; it is neither its purpose nor its legitimate motive.

I would like now to touch briefly on the final theme: the relation between instinct and reason as the ground of the pragmatic maxim and as the explanation of the continuity between theory and prac- 
tice. In Peirce's opinion all scientific inquiry supposes a Realism, in the sense that the Real is co-extensive with the Knowable. There is no Kantian noumenon. If this is so, the Real constitutes a network of relations such that everything is connected with everything else or, to put it another way, the Real is everywhere continuous. Natura non facit saltus. This continuous Real is systematically explored through abduction, deduction, and induction. But since neither deduction nor induction yields any new knowledge about the Real, abduction is at the heart of all discovery. But, according to Peirce, abduction is nothing but instinctive reason. It is the power nature provided man in the course of evolution for survival in the evolving cosmos by enabling him to meet and to help bring about radically new situations. While it is true that Peirce, on the one hand, rejects as improbable any instinct for logicality in the sense of a feeling of logical connection which guarantees the correctness of any inference, still, on the other hand, he admits instinctive reason which, while it may be wrong more often than it is right, nonetheless is right often enough to allow us to discover some of Nature's Laws.

Galileo appeals to il lume naturale at the most critical stages of his reasoning. Kepler, Gilbert and Harvey-not to speak of Copernicus - substantially rely upon an inward power, not sufficient to reach the truth by itself, but yet supplying an essential factor to the influences carrying their minds. It is certain that the only hope of retroductive reasoning ever reaching the truth is that there may be some natural tendency toward an agreement between the ideas which suggest themselves to the human mind and those who are concerned in the laws of nature. $(1.80-81)$

Peirce, perhaps under the influence of Chauncey Wright, accepted a thoroughgoing evolutionism. He held that human reason must be an evolutionary development of animal instinct.

Side by side, then, with the well-established proposition that all knowledge is based on experience . . . we have to place this other equally important truth, that all human knowledge, up to the highest flights of science, is but the development of our inborn animal instincts. (2.754)

Peirce bases this opinion precisely on il lume naturale, the faculty for guessing right, without which scientific knowledge would have been impossible. 
For Peirce, then, reason is itself in continuity with instinct, and so might be considered to be man's specific instinctive power. It is an evolutionary development of the instinct of feeding and breeding. This led him to identify his pragmaticism with a position which he called Critical Commonsensism. As the name suggests, it is sympathetic to the Scottish School and yet is critical of some details. There are some beliefs which are indubitable because they are instinctive. Such beliefs are acritical and essentially vague. Nonetheless they are at the very heart of the power of reason itself and function as a necessary counterbalance to scientific fallibilism. That there is order in the world is one such belief. That God is real is another (see 5.508, 8.262). ${ }^{8}$

Instinctive reason with its vague instinctive beliefs inserts man into an evolving world not merely as a product of that creative process but also as an active cooperative agent. Since through reason he has the power of reflection and a high degree of self-control, man holds the unique and privileged position of co-creator (5.403, note 3).

Peirce describes the highest end which man can pursue, the admirable in itself, in terms of "concrete reasonableness":

I do not see how one can have a more satisfying ideal of the admirable than the development of Reason so understood. The one thing whose admirableness is not due to an ulterior reason is Reason itself comprehended in all its fullness, so far as we can comprehend it. Under this conception, the ideal of conduct will be to execute our little function in the operation of creation by giving a hand toward rendering the world more reasonable, whenever, as the slang is, it is "up-to-us to do so." (1.615)

\section{Notes}

1. For an account of this episode in Peirce's life and for the correspondence between Peirce and James, see R. B. Perry, The Thought and Character of William James. II. Philosophy and Psychology (Boston: Little, Brown, 1935), pp. 417-21.

2. Royce's letter to James in 1901 is cited by Perry, ibid., p. 421.

3. "By a positive science I mean an inquiry which seeks for positive knowledge; that is, for such knowledge as may conveniently be expressed in a categorical proposition" (5.39). 
4. For the relation of philosophy's branches to the categories, see my Charles S. Peirce: On Norms and Ideals (Amherst: University of Massachusetts Press, 1967), pp. 18-24.

5. For a treatment of "immediate relevance" in philosophy, see my "The Irrelevance of Philosophy," Thought, 49, No. 193 (June 1974), $145-55$.

6. See my Norms and Ideals, pp. 3-7, and chaps. 5 and 6 below.

7. Peirce went so far as to revise the maxim several times to make his meaning clear. See, for example, 5.18.

8. For an extended development of Peirce's views on God, see chap. 12 below. 